\title{
Presynaptic Glutamate Levels in Tonic and Phasic Motor Axons Correlate with Properties of Synaptic Release
}

\author{
Oleg Shupliakov, ${ }^{1}$ Harold L. Atwood, ${ }^{2}$ Ole Petter Ottersen, ${ }^{3}$ Jon Storm-Mathisen, ${ }^{3}$ and Lennart Brodin ${ }^{1}$ \\ ${ }^{1}$ Nobel Institute for Neurophysiology, Department of Neuroscience, Karolinska Institutet, S-171 77 Stockholm, \\ Sweden, ${ }^{2}$ MRC Group in Nerve Cells and Synapses, Department of Physiology, University of Toronto, Toronto, \\ Ontario, Canada M5S 1A8, and ${ }^{3}$ Department of Anatomy, Institute of Basic Medical Sciences, University of Oslo, \\ $\mathrm{N}-0317$ Oslo, Norway
}

Synaptic glutamate release involves the accumulation of cytoplasmic glutamate in synaptic vesicles, whereafter it is released by triggered exocytosis. As glutamatergic terminals are known to be functionally diverse it was of interest to examine whether the presynaptic glutamate supply differs between individual axon terminals with distinct release properties. The glutamatergic terminals in the crustacean neuromuscular system system comprise a "phasic" type which shows fatigue of release during repetitive stimulation, and a "tonic" type which can maintain transmission for long periods. Quantitative immunogold analysis showed that the axons in a tonic nerve innervating slow muscles in the abdomen contained two times higher levels of glutamate labeling over axoplasmic matrix and over mitochondria, as compared to the corresponding elements in a phasic nerve. Similar results were obtained when adjacent phasic and tonic axons in a mixed nerve innervating leg muscles were compared. In the terminal regions of tonic and phasic axons the glutamate labeling differed correspondingly over axoplasmic matrix and mitochondria, while the synaptic vesicles showed a similar strong accumulation of labeling in both types of terminal. The level of labeling for glutamine, a glutamate precursor, was closely similar in phasic and tonic axons. The axoplasmic glutamate concentration was estimated to be in the low millimolar range, through comparison with coprocessed conjugates with known glutamate concentration. These results show that fatigue-resistant tonic axons and terminals contain higher levels of glutamate than fatiguable phasic axons, presumably representing an adaptation to the markedly different impulse activities in the two types of neuron. The axonal glutamate concentrations are in the range of the $K_{m}$ value for vesicular glutamate transport. Thus in tonic axons the high glutamate level appears to promote an efficient refilling of synaptic vesicles during sustained release, while in phasic axons the refilling

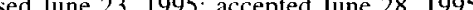

This work was supported by the Swedish Medical Research Council (Grant No. 11287 L.B.), Jeanssons Stiftelser (L.B.), Stiftelsen Lars Hiertas Minne (O.S.), the Medical Research Council of Canada (H.L.A.), and the Norwegian Research Council (O.P.O., J. S.-M.). We are indebted to Dr. L. Marin, University of Toronto, who assisted in preparing sectioning, and examining specimens selected for electron microscopy, and to Dr. R. Hill and Dr. B. Rydquist for their assistance in the initial part of this study.

Correspondence should be addressed to Lennart Brodin at the above address. Copyright (O) 1995 Society for Neuroscience $0270-6474 / 95 / 157168-13 \$ 00500 / 0$
}

should be slower which is compatible with an infrequent release.

[Key words: synapse, synaptic vesicle, mitochondria, glutamate, glutamine, neurotransmitter]

The physiological properties of nerve terminals show considerable variability, attributable in large measure to differences in synaptic properties. This heterogeneity applies to the amount of transmitter released per impulse, and to short- and long-term modulation of the synaptic output, as well as to the fatiguability of a terminal during periods of intense release (Atwood, 1976; McNaughton, 1980; Atwood and Wojtowicz, 1986; Bower and Haberly, 1986; Koerber and Mendell, 1991; Brodin and Shupliakov, 1994). Glutamate is the principal excitatory transmitter in the vertebrate CNS and in the neuromuscular system of arthropods. The most detailed knowledge about distinct classes of glutamatergic terminals stems from studies of neuromuscular synapses in crustaceans. 'The glutamatergic motor neurons can be broadly divided into phasically and tonically active types (Kennedy and Takeda, 1965a,b). The "phasic" ncurons, which primarily innervate fast muscles, or fast-acting muscle fibers in mixed muscles, are active only for brief periods, while the "tonic" neurons innervating slow and mixed muscles are more frequently active (Atwood et al., 1991). Upon repetitive stimulation terminals of phasic neurons release large amounts of transmitter for the first few impulses, but fatigue rapidly with maintained stimulation. In contrast, the terminals of tonic neurons produce a synaptic response which is resistant to depression and exhibits short-term facilitation (Lnenicka, 1991). Ultrastructural studies have shown that phasic terminals tend to contain few mitochondria and have relatively small clusters of synaptic vesicles at active zones of synapses (Atwood and Jahromi, 1977). The tonic terminals, on the other hand, contain larger and more numerous mitochondria, and the clusters of synaptic vesicles are larger (Jahromi and Atwood, 1974).

The neuronal metabolism of glutamate, and the properties of the vesicular and plasma membrane transport systems for glutamate have been extensively investigated in different preparations of the mammalian CNS (Naito and Ueda, 1985; Fonnum, 1993; Nicholls, 1993; Danbolt et al., 1994; Kanai et al., 1994; Wang and Floor, 1994). As yet, however, little is known about the regulation of the transmitter pool of glutamate at the level of the single terminal. The phasic and tonic glutamatergic terminals in crayfish provide a unique model to examine the supply of glutamate in terminals with known properties. We have used 


\section{A}

B

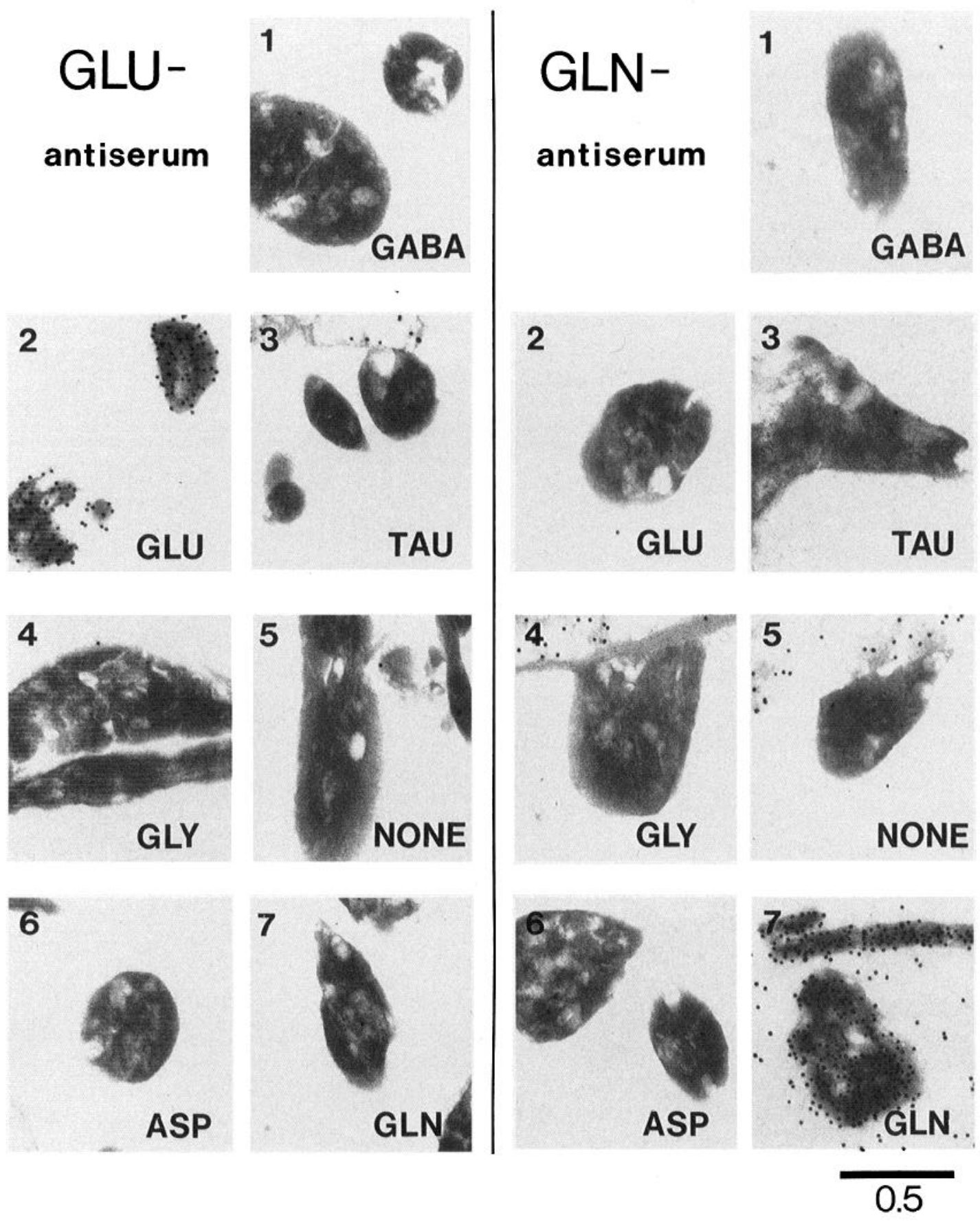

Figure 1. Evaluation of the selectivity of the glutamate and glutamine immunolabeling in the present series of experiment. $A$ and $B$, Electron micrographs of areas of test sections incubated with glutamate and glutamine antisera, respectively. Test sections contained glutaraldehyde-brain macromolecule conjugates of six amino acids: GABA, glutamate $(G L U)$, taurine $(T A U)$, glycine $(G L Y)$, aspartate $(A S P)$, and glutamine $(G L N)$. NONE, Conjugates made by reacting the brain macromolecule extract with glutaraldehyde without addition of amino acids (for details, see Ottersen, 1987). Note the selective concentration of gold particles $(15 \mathrm{~nm})$ over the conjugates containing glutamate and glutamine. Tissue sections used as spacers in between the test conjugates are visible on some of the micrographs. These tissue sections show labeling for both glutamate and glutamine. Scale bar: $A, 1 \mu \mathrm{m} ; B, 0.5 \mu \mathrm{m}$.

an ultrastructural immunocytochemical procedure, which allows a quantification of amino acids in fixed tissue (Ottersen, 1989; Zhang et al., 1993) to determine the subcellular distribution of glutamate in individual axons and terminals. The results provide evidence for a differential regulation of the glutamate supply in "phasic" and "tonic" axon terminals.

A preliminary report has appeared in abstract form (Shupliakov et al., 1994a). 


\section{Materials and Methods}

The experiments were performed on crayfish (Pacifastacus leniusculus and Procambarus clarkii). The animals were obtained from commercial suppliers and maintained in circulating fresh water at $18^{\circ} \mathrm{C}$. Before dissection, the animals were immobilized by cooling on ice. The nerves selected for analysis were (1) the phasic motor nerve to the fast (deep) abdominal extensor muscles, which consists of five excitatory and one inhibitory axon (Parnas and Atwood, 1966); (2) the tonic motor nerve to the slow (superficial) abdominal flexor muscles, which consists of five excitatory and one inhibitory axon (Kennedy and Takeda, 1965a,b); (3) the motor nerve to the carpopodite extensor muscle in the walking leg, which consists of two excitatory axons (one tonic, one phasic) and one inhibitory axon, a branch of the "common" inhibitor of the leg (Wiens and Wolf, 1993). The latter preparation offered the advantage of immediate proximity of the two different motor axons, which could be fixed and processed together, thus minimizing problems of comparing phasic and tonic axons in different nerves or specimens. In addition, it was possible to find adjacent neuromuscular junctions of the two axons in this preparation.

The different nerves and muscles were quickly dissected in oxygenated crayfish saline at $4^{\circ} \mathrm{C}$ (van Harreveld 1936; Wojtowicz and Atwood, 1984), and fixed for $4 \mathrm{hr}$ in $3 \%$ glutaraldehyde in $0.1 \mathrm{M}$ phosphate buffer ( $\mathrm{pH} 7.4$ ). After washing in phosphate buffer for $4 \mathrm{hr}$ the specimens were postfixed for $1 \mathrm{hr}$ in $1 \%$ osmium tetroxide in the same buffer, thereafter dehydrated in alcohol and embedded in Durcupan ACM, Flu$\mathrm{ka}$. In the experiments with separate phasic and tonic nerves to the superficial flexor and the deep extensor muscles of the abdomen, the nerves were processed together and embedded in the same block of resin to minimize possible errors due to differential treatment of the tissue.

Semithin sections ( $0.5 \mu \mathrm{m}$ thickness) were cut and mounted on glass slides, then processed with anti-GABA and anti-glutamate antisera (see below) according to the peroxidase-antiperoxidase (PAP) procedure, following removal of the resin by sodium ethanolate as described elsewhere (Somogyi et al., 1984; Ottersen, 1987). To monitor the specificity, the tissue sections were always incubated together with semithin test sections (see Fig. 3) containing fixation complexes of six amino acids (Ottersen, 1989; Zhang et al., 1993). For electron microscopy, ultrathin sections were cut on an ultrotome, and collected on nickel mesh grids or Formvar-coated slot grids. The immunogold procedure, based on that of Somogyi and Hodgson (1985), has been described previously (Ottersen, 1987, 1989). Briefly, the sections were treated with $1 \% \mathrm{HIO}_{4}(7$ min) and $9 \% \mathrm{NaIO}_{4}(15 \mathrm{~min})$, preincubated with $1 \%$ human serum albumin in Tris-phosphate buffered saline (TPBS; 20min), and then incubated for $2-4 \mathrm{hr}$ with anti-glutamate or anti-glutamine antiserum (see helow). After a brief rinse in polyethyleneglycol $(50 \mathrm{mg} / 100 \mathrm{ml}$ in TrisHCl buffer, $\mathrm{pH} 7.4$ ), the sections were incubated with goat antirabbit IgG coupled to colloidal gold particles (diameter $15 \mathrm{~nm}$; Amersham), diluted 1:20 in the same polyethyleneglycol solution. The sections were stained with uranyl acetate and lead citrate and examined and photographed in a Philips CM12 electron microscope. As a control for the specificity of the immunological label, the tissue sections were incubated together with ultrathin test sections containing fixation complexes of amino acids (Fig. 1; Ottersen, 1987, 1989).

The following primary antisera were used (all raised in the laboratory): glutamate (stock identification no. 03), glutamine (no. 34), and GABA (no. 990), all of which were raised in rabbits by immunization with glutaraldehyde-protein-amino acid conjugates essentially as originally described (Storm-Mathisen et al., 1983). The antisera have been extensively characterized and their properties described previously (see Laake et al., 1986; Ji et al., 1991; Zhang et al., 1991; Shupliakov et al., 1993). One day before incubation of the tissue sections, the antisera were diluted with TPBS and appropriate amino acid glutaraldehyde (G) complexes were added in order to remove cross-reactive antibodies. The following combinations were used: anti-glutamate 03 absorbed with Sepharose-BSA-G-GABA 1:600 and preincubated with aspartate-G (300 $\mu \mathrm{M})$ and glutamine-G $(100 \mu \mathrm{M})$; anti-glutamine 34 absorbed with Sepharose-BSA-G-glutamate and mycobacteria from the adjuvant 1:500, with aspartate-G $(150 \mu \mathrm{m})$, glutamate-G $(200 \mu \mathrm{m})$ and GABA-G $(100$ $\mu \mathrm{m})$; anti-GABA 990 1:600 preincubated with $\beta$-alanine-G $(300 \mu \mathrm{M})$.

In control experiments in which the primary antiserum had been omitted or substituted with preimmune serum, the tissue sections were unlabeled. A complete blockade of the immunostaining with the glutamine and glutamate antisera was obtained by adding $300 \mu \mathrm{M}$ of glutamate- $G$ or glutamine- $G$ to the corresponding antisera.

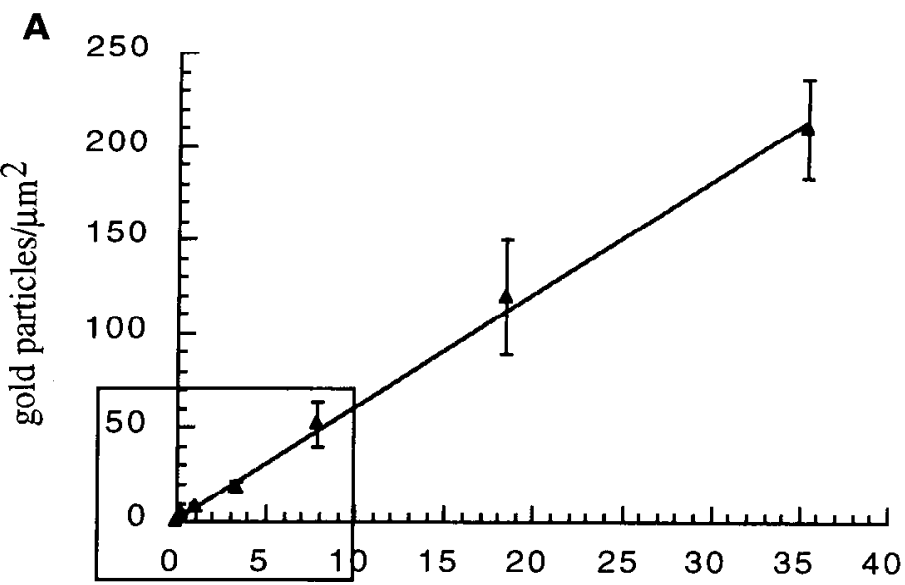

B

$\mathrm{mmol} / \mathrm{l}$ fixed glutamate
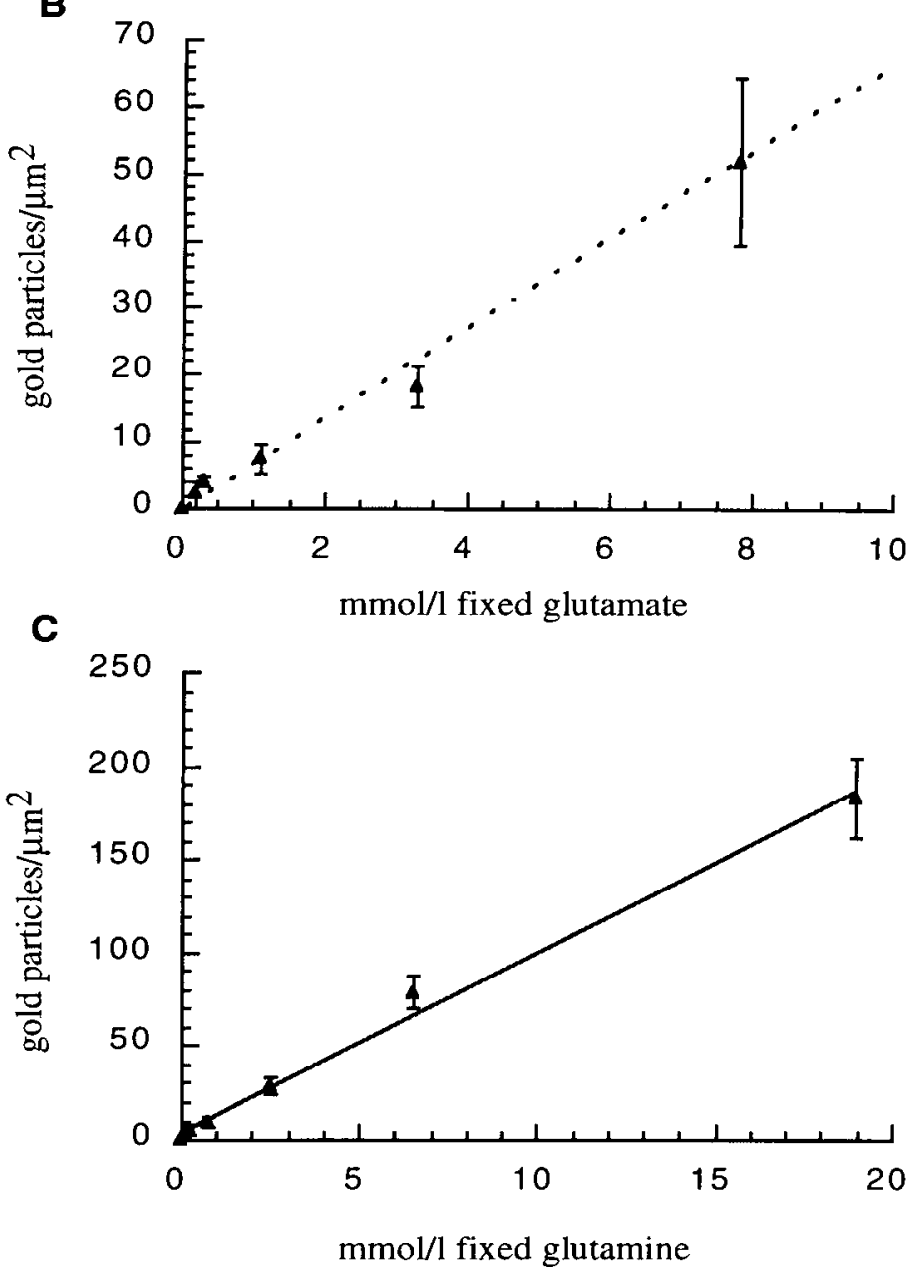

Figure 2. Relationship between the gold particle density (gold particles $/ \mu \mathrm{m}^{2}$ ) and the concentration (mmol/liter) of fixed glutamate $(A, B)$ and glutamine $(C)$ in one of the experiments. The framed area in $A$ is shown at higher resolution in $B$. The data were obtained by quantifying the immunolabeling in a graded series of conjugates with known concentrations of fixed amino acids and treated with $\mathrm{OsO}_{4}$ similar to the tissue sections (for details, see Ottersen, 1989). Each point represents the mean \pm SEM of values for 8-10 profiles. The regression line for each experiment $(A, C)$ is indicated by solid line $(r>0.98$; in each case). The dashed line in $B$ is a polynomial (second order) curve fit, which gives a better approximation of the experimental data at low glutamate concentrations. 

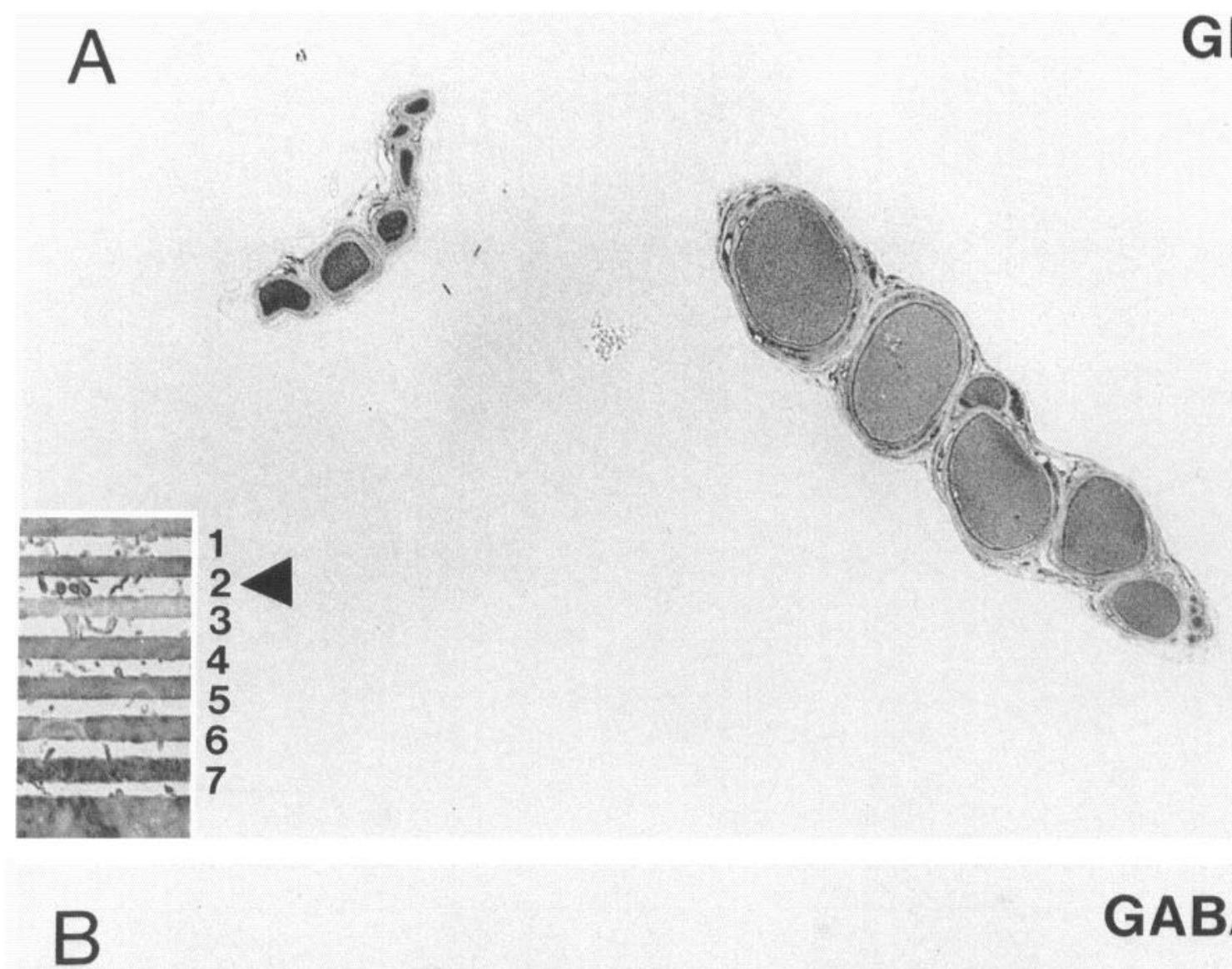

\section{GABA}
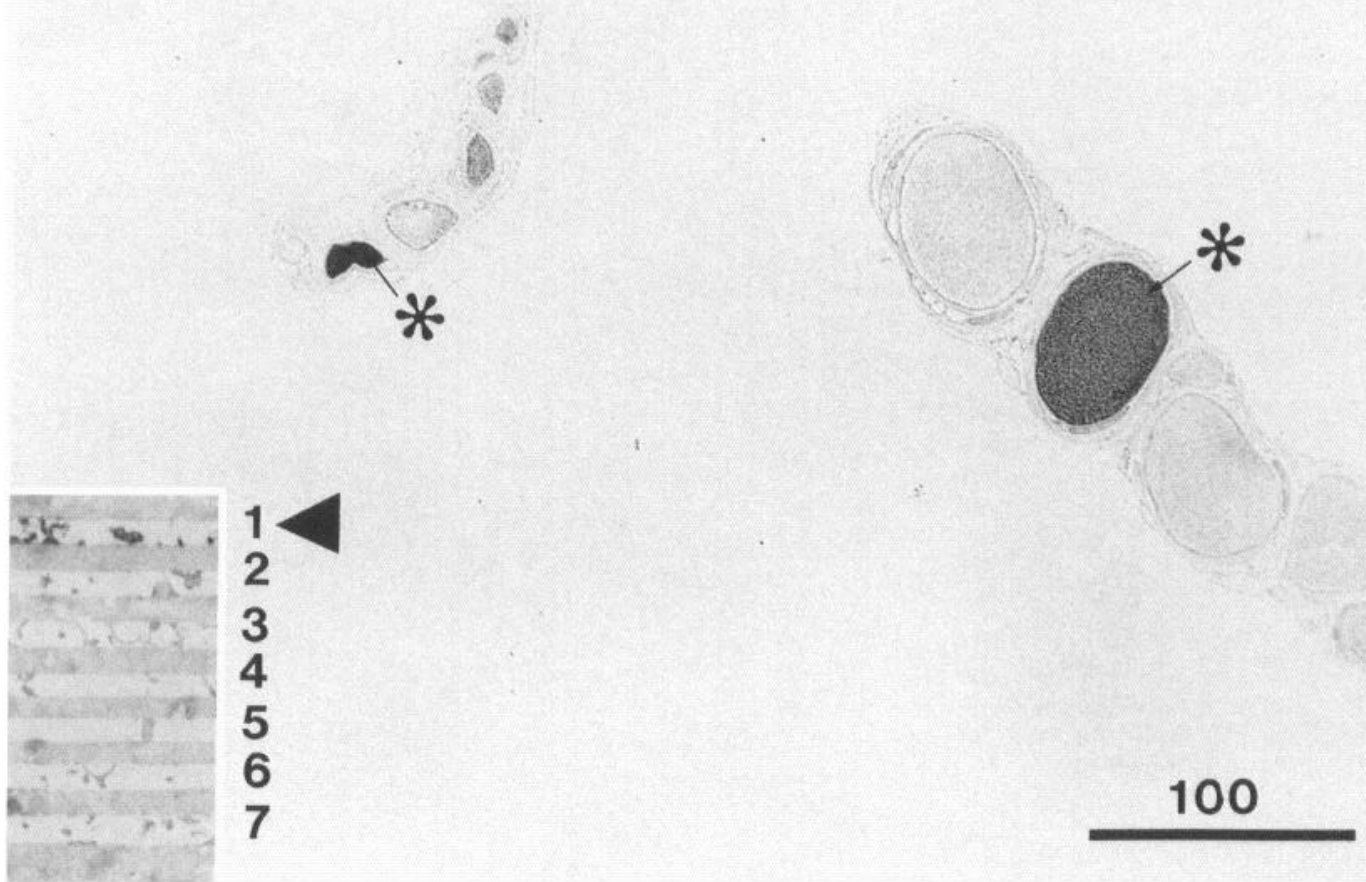

Figure 3. Light microscopic distribution of glutamate and GABA immunoreactivity in tonic and phasic nerves of the crayfish abdomen. The photomicrographs show two adjacent semithin $(0.5 \mu \mathrm{m})$ sections incubated with glutamate $(A)$ and GABA $(B)$ antiserum, respectively. Each section contains one nerve to the superficial flexor muscle (tonic; to the left), and one nerve to the deep extensor muscle (phasic; to the right). The asterisks in $B$ indicate the GABA-immunoreactive axon in each nerve that was excluded from the analysis. The insets in $A$ and $B$ show sections of the test sandwhich which were stained along with the tissue section in each case. The test sandwich is composed of amino acid-glutaraldehyde-brain protein conjugates with: 1 , GABA; 2 , glutamate; 3 , taurine; 4 , glycine; 5 , none (see Fig. 1 ); 6 , aspartate; 7 , glutamine, spaced by sections of rat brain tissue. The arrowheads indicate bands corresponding to the glutamate $(A)$ and GABA $(B)$ conjugates, respectively, which exhibit a selective labeling in each case. Scale bar for $A$ and $B, 100 \mu \mathrm{m}$. 


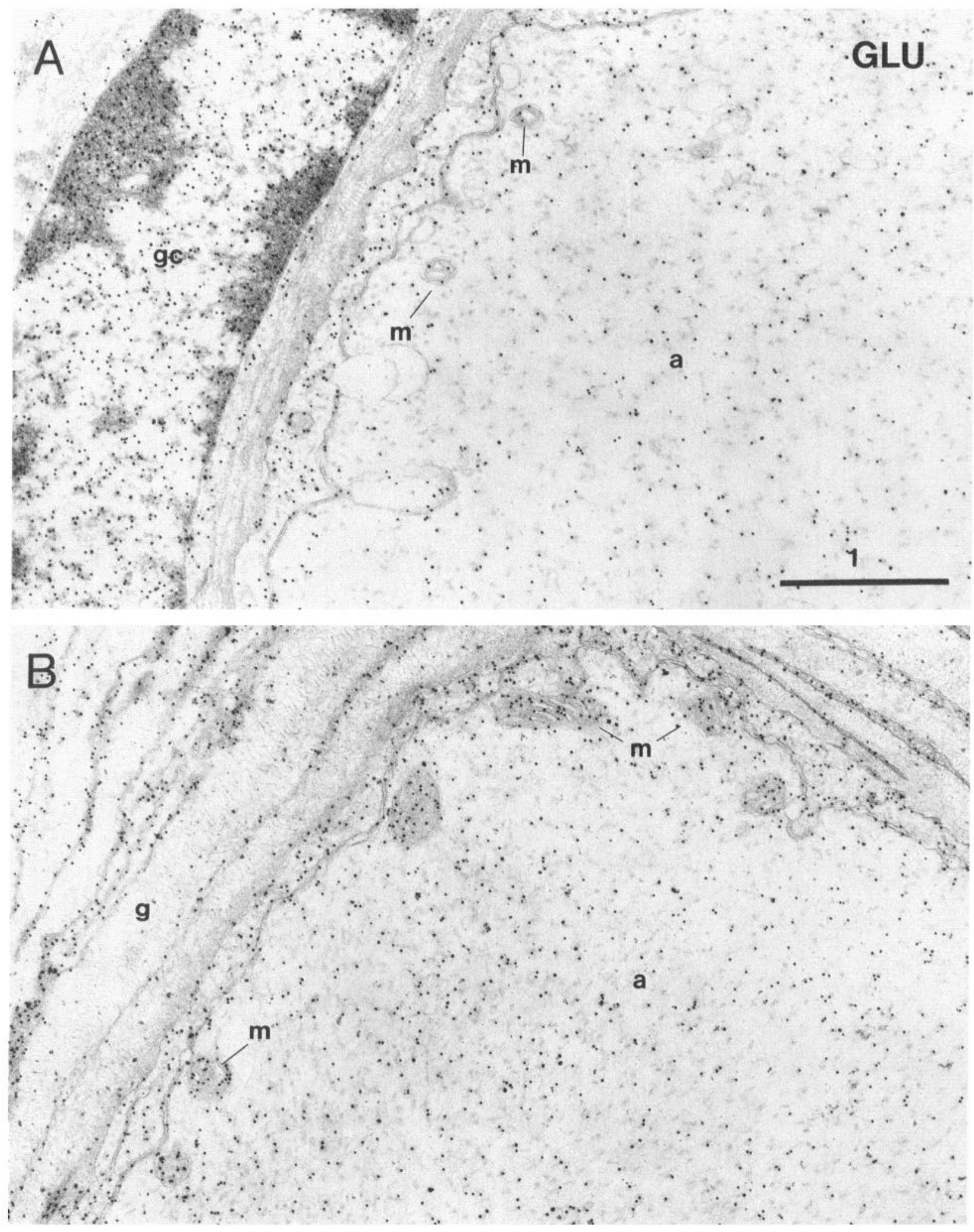

Figure 4. Glutamate immunogold-labeling in axons of phasic and tonic nerves of the crayfish abdomen. A, Axon innervating the deep flexor muscle (phasic). $B$, Axon innervating the superficial extensor muscle (tonic). Note that the axoplasmic matrix (a) in the phasic axon contains a lower density of gold particles than that in the tonic axon. The axonal mitochondria $(m)$ exhibit a similar difference. Note also the difference in the number and size of the mitochondria between the two axons. The glial cell processes $(g)$ surrounding both types of axon show a moderate level of labeling, while the glial cell bodies $(g c)$ are more intensely labeled. Scale bar, $1 \mu \mathrm{m}$. 
Electron micrographs taken from immunostained sections were analysed on a digitizing tablet coupled to a computer. The gold particles over different tissue profiles and subcellular compartments were counted and the particle densities were determined using the MORFOREL program (Blackstad et al., 1990). Statistical evaluation of the data was carried out by means of a commercial statistical package (SPSS/PC+). In experiments with the motor nerve to the carpopodite extensor muscle in the walking leg the number of microtubules and neurofilaments were in addition quantified in the axoplasmic compartment. In order to ensure that there would not be a bias by local differences within an axon the densities of gold particles, neurofilaments and microtubules, respectively, were in each type of axon measured in three different parts of the axon. Thus, the field of view of axoplasmic matrix was randomly divided into three sectors, each of which was analyzed separately. While the values given represent an average of the three measurements the densities were in all cases closely similar in the different sectors of an axon.

Each tissue section contained a region of tissue-free plastic in which the background level of gold particles could be determined. This level was below 1 particle per $\mu \mathrm{m}^{2}$ in all experiments.

For estimation of the relationship between gold particle density and antigen concentration, the ultrathin tissue sections were coprocessed with sections from a laminated series of OsO4-treated conjugates, containing different concentrations of glutamate and glutamine (for details, see Ottersen, 1989). In both cases a linear relationship between the density of gold particles and the amino acid concentration was obtained throughout most of the concentration range (Fig. 2), although at the lowest concentrations this was not strictly linear (Fig. $2 B$; cf. Ottersen et al., 1992; Shupliakov et al., 1992).

\section{Results}

\section{Light-microscopic analysis of phasically and tonically active} nerves

To examine the levels of glutamate immunoreactivity in axons belonging to terminals with well-defined properties, we first focused on two types of muscle nerve in the crayfish abdomen: the phasically active axons innervating the rapidly contracting deep extensor muscles of the abdomen, and the tonically active axons innervating the slowly contracting superficial flexor muscles (Kennedy and Takcda, 1965a,b; Parnas and Atwood, 1966). In both nerves five of the six axons are excitatory, and one is inhibitory.

The light microscopic distribution of glutamate and GABA immunoreactivity was initially surveyed in adjacent semi-thin sections (Fig. $3 A, B$ ). A single axon within each nerve showed prominent GABA immunoreactivity (Fig. $3 B$ ). The inhibitory axon could thus be easily identified and excluded from the subsequent analysis for glutamate.

In sections labeled with glutamate antiserum, immunolabeling occurred in all components of the two nerves (Fig. $3 A$ ). The most intense labeling was present in cytoplasmic areas of axons and glial cell bodies, while the processes surrounding the axons (identified as glial processes in adjacent ultrathin sections) displayed a moderate labeling. The tonic flexor axons displayed a more intense glutamate labeling than the phasic extensor axons, although the PAP-post-embedding method is to be considered qualitative rather than quantitive (Walberg et al., 1990).

\section{Electron microscopic analysis of phasically and tonically} active nerves

Electron microscopic analysis of the deep extensor and superficial flexor axons showed that they exhibited typical features of phasic and tonic axons, respectively (Fig. 4). Thus, the deep extensor axons (Fig. 4A) contained a lower density of mitochondria than the superficial flexor axons (Fig. $4 B$ ). Individual mitochondria were also smaller in phasic axons. Most of the mitochondria were located in the vicinity of the axolemma in
Table 1. Mean gold particle densities in tonic and phasic motor axons and surrounding glial processes in the nerves to abdominal flexor (tonic) and extensor (phasic) muscles

\begin{tabular}{|c|c|c|c|c|}
\hline \multirow[b]{2}{*}{$\begin{array}{l}\text { Exp. } \\
\text { no. }\end{array}$} & \multirow[b]{2}{*}{$\begin{array}{l}\text { Type of } \\
\text { neIve }\end{array}$} & \multicolumn{2}{|c|}{$\begin{array}{l}\text { Density of gold particles } / \mu \mathrm{m}^{2} \\
(\text { mean } \pm \mathrm{SEM})\end{array}$} & \multirow[b]{2}{*}{$\begin{array}{l}\text { Glial } \\
\text { processes }\end{array}$} \\
\hline & & $\begin{array}{l}\text { Axoplasmic } \\
\text { matrix }\end{array}$ & $\begin{array}{l}\text { Axonal } \\
\text { mitochondria }\end{array}$ & \\
\hline \multirow[t]{2}{*}{1} & Tonic & $\begin{array}{l}42.2 \pm 0.8 \\
n=5\end{array}$ & $\begin{array}{l}278.0 \pm 15.9 \\
n=15\end{array}$ & $\begin{array}{l}28.1 \pm 1.5 \\
n=10\end{array}$ \\
\hline & Phasic & $\begin{array}{l}17.2 \pm 4.4 \\
n=5\end{array}$ & $\begin{array}{l}106.0 \pm 25.5 \\
n=8\end{array}$ & $\begin{array}{l}2.3 .4 \pm 2.0 \\
n=10\end{array}$ \\
\hline \multirow[t]{2}{*}{2} & Tonic & $\begin{array}{l}6.3 \pm 0.5 \\
n=5\end{array}$ & $\begin{array}{l}120.5 \pm 10.6 \\
n=20\end{array}$ & $\begin{array}{l}9.1 \pm 1.1 \\
n=10\end{array}$ \\
\hline & Phasic & $\begin{array}{l}3.5 \pm 0.2 \\
n=5\end{array}$ & $\begin{array}{l}41.0 \pm 16.8 \\
n=13\end{array}$ & $\begin{array}{l}10.8 \pm 2.1 \\
n=10\end{array}$ \\
\hline \multirow[t]{2}{*}{3} & Tonic & $\begin{array}{l}22.4 \pm 1.9 \\
n=5\end{array}$ & $\begin{array}{l}123.9 \pm 14.0 \\
n=18\end{array}$ & $\begin{array}{l}14.9 \pm 0.7 \\
n=10\end{array}$ \\
\hline & Phasic & $\begin{array}{l}8.5 \pm 1.4 \\
n=6\end{array}$ & $\begin{array}{l}41.7 \pm 10.6 \\
n=17\end{array}$ & $\begin{array}{l}14.4 \pm 0.8 \\
n=10\end{array}$ \\
\hline \multirow[t]{2}{*}{4} & Tonic & $\begin{array}{l}38.8 \pm 5.5 \\
n=4\end{array}$ & $\begin{array}{l}286.1 \pm 16.5 \\
n=18\end{array}$ & $\begin{array}{l}24.6 \pm 1.5 \\
n=10\end{array}$ \\
\hline & Phasic & $\begin{array}{l}17.4 \pm 2.0 \\
n=5\end{array}$ & $\begin{array}{l}90.4 \pm 14.8 \\
n=10\end{array}$ & $\begin{array}{l}23.0 \pm 2.4 \\
n=13\end{array}$ \\
\hline
\end{tabular}

$n$, Number of mitochondria, axons and glial profiles included in the analysis.

both axon types. Quantification of the area covered by mitochondrial profiles $\left(\mu \mathrm{m}^{2}\right)$ per length of axolemma $(\mu \mathrm{m})$, within a distance of $2 \mu \mathrm{m}$ from the membrane, gave an almost threefold higher value for the tonic flexor axons $(0.6 \pm 0.3$ and $1.5 \pm 0.2$ $\mu \mathrm{m}^{2} /$ per $\mu \mathrm{m}$, for the deep extensor and tonic flexor axons, respectively; $\pm \mathrm{SEM}, n=6$ ).

After immunogold labeling with glutamate antiserum, the phasic extensor axons (Fig. $4 A$ ) clearly exhibited a lower density of gold particles than the tonic flexor axons (Fig. 4B). Quantitative analysis (Table 1) showed that the particle density over axoplasmic matrix of the phasic axons was approximately half of that in the tonic axons. A similar difference was observed when the labeling over mitochondria was compared (Table 1). The particle density over the surrounding glial cell processes, however, did not differ significantly between the two types of axon (Table 1). If a linear correlation between the labeling efficiency of the glutamate antiserum (density of gold particles/ $\mu \mathrm{m}^{2}$ ) and the concentration of fixed glutamate in the tissue is assumed (see Materials and Methods and Fig. 2), the difference in glutamate concentration between tonic and phasic elements becomes approximately twofold. If the polynomial curve fit (Fig. $2 B$ ) is used at low glutamate concentrations, however, the difference will be even larger. It can thus be concluded that the tonically active flexor axons contain a concentration of fixed glutamate which is at least two times higher than that in the phasically active extensor axons.

\section{Glutamate immunoreactivity in adjacent phasic and tonic} motor axons of similar size

The amount of glutamate retained during aldehyde fixation depends to some extent on factors influencing the penetration of the fixative as well as on the content of protein within the tissue elements (Storm-Mathisen and Ottersen, 1990). It is thus possible that the fixation is more efficient in the tonic axons to the superficial flexor muscles, which have a smaller diameter (Fig. 
A

\section{GABA}

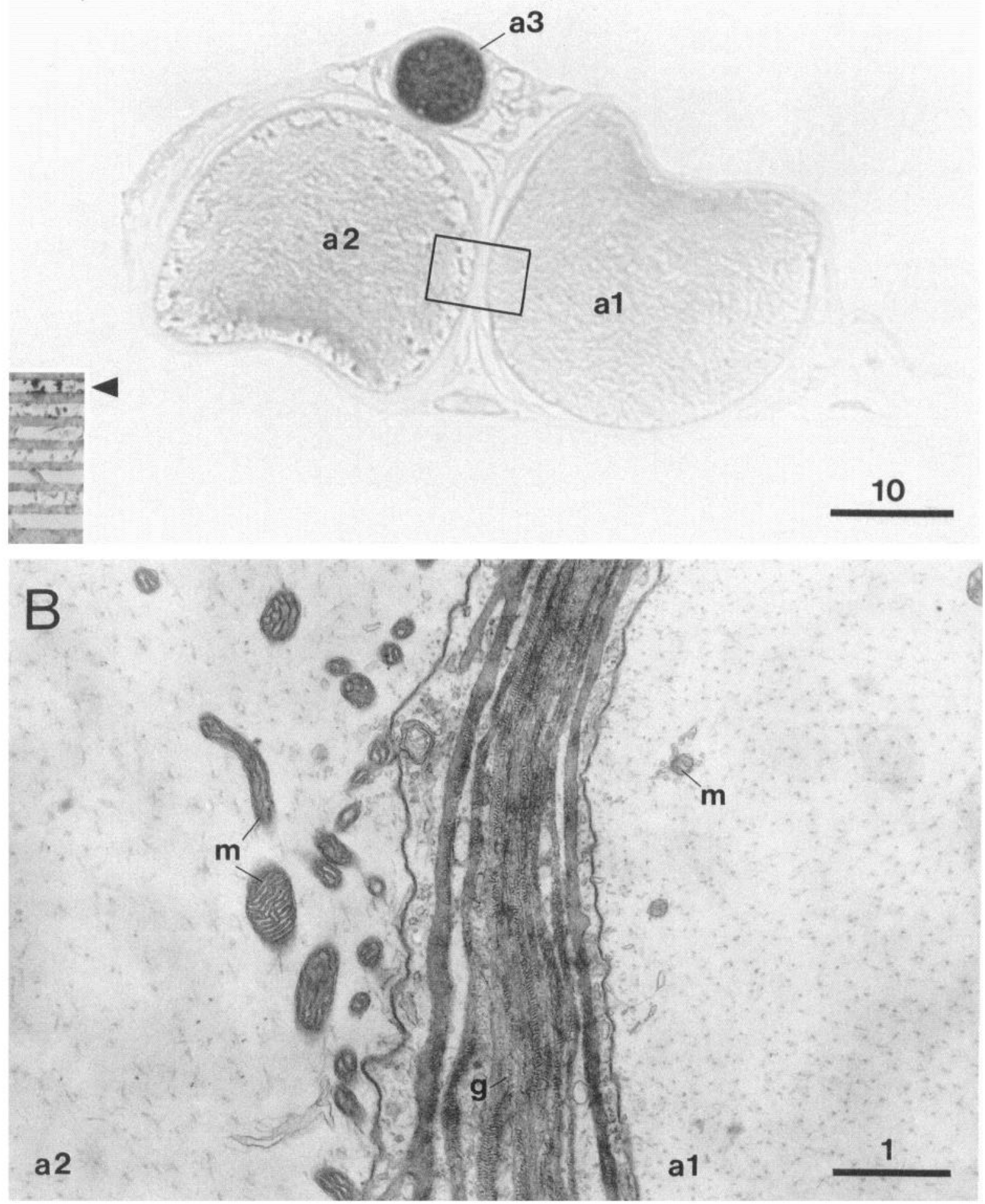

Figure 5. Morphological features of phasic and tonic axons in a mixed nerve innervating the main extensor muscle of the walking leg. A, Light micrograph of a semithin section incubated with GABA antiserum, to mark the inhibitory axon (a3). The excitatory axons (al and $a 2)$, which are approximately equal in size, are not labeled by the GABA antiserum. The inset in $A$ shows the test section incubated along with the tissue section. The band in the test section corresponding to the GABA conjugate is selectively labeled. $B$, Electron micrograph taken from an adjacent ultrathin section, which includes the area indicated with a rectangle in $A$. Note that the phasic axon al contains fewer and smaller mitochondria than the tonic axon $a 2$. Scale bars: $A, 10 \mu \mathrm{m} ; B, 1 \mu \mathrm{m}$ 

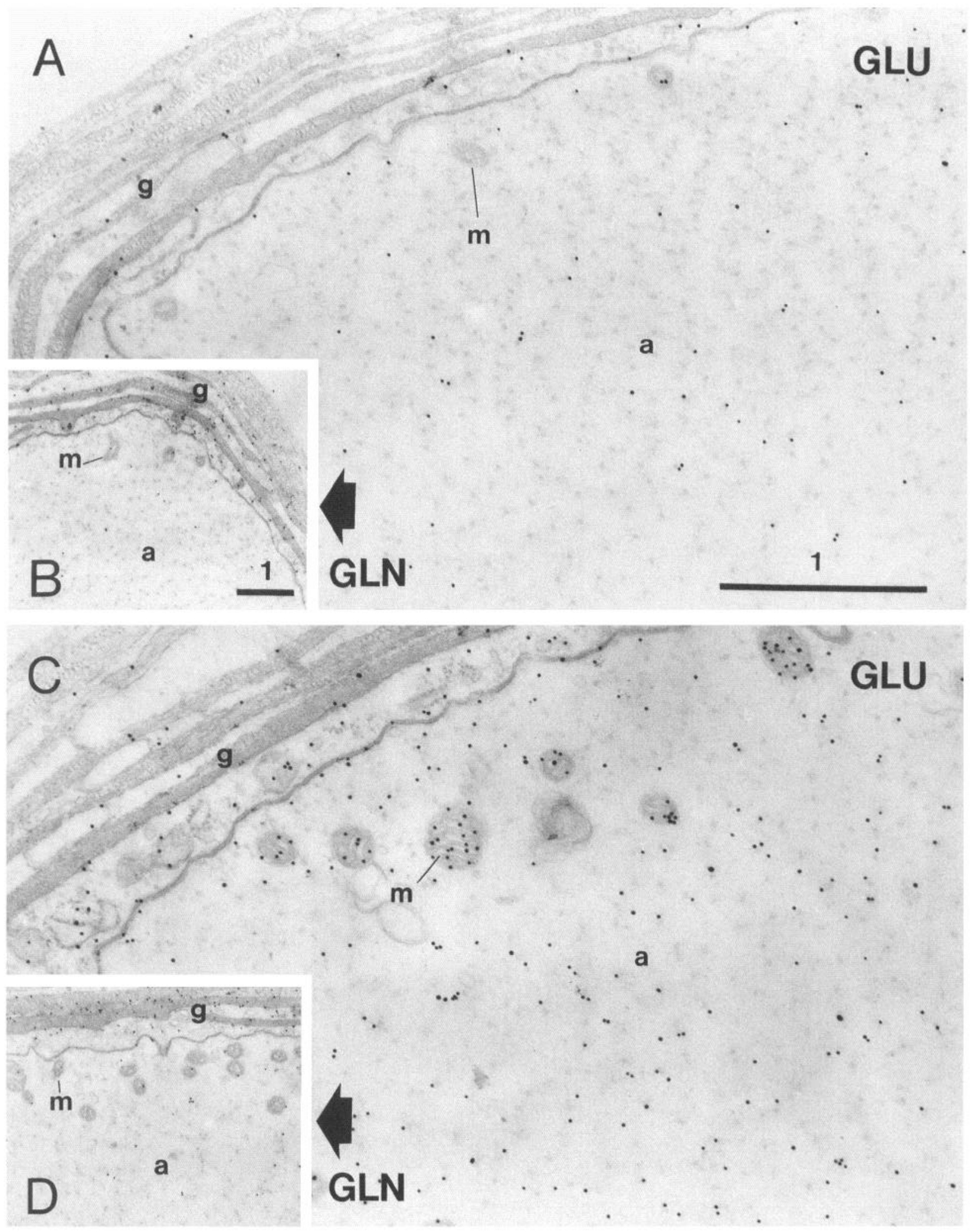

Figure 6. Glutamate immunogold-labeling in morphologically identified phasic $(A)$ and tonic $(C)$ axons innervating the main extensor muscle of the walking leg. Note that the axoplasmic matrix $(a)$ and mitochondria $(m)$ in the phasic axon $(A)$ show a lower density of gold particles than in the tonic axon. Note also the lower number of mitochondrial profiles in the phasic axon $(C)$. The general level of labeling was lower in this experiment than in that shown in Figure 4 , since only one side of the section was exposed to the antiserum. $B$ and $D$ show parts of adjacent ultrathin sections of the same axons stained with glutamine antiserum. Note that that the levels of glutamine labeling are approximately equal in the two types of axon. The glial cell processes $(g)$ adjacent to both axons show an accumulation of glutamine immunoreactivity. Scale bars: $A$, $C$ and $B, D, 1 \mu \mathrm{m}$. 
Table 2. Mean gold particle densities, neurofilaments, and microtubules in excitatory axons in the mixed nerve to the carpopodite extensor muscle in the walking leg

\begin{tabular}{|c|c|c|c|c|c|c|}
\hline \multirow[b]{3}{*}{$\begin{array}{l}\text { Exp. } \\
\text { no. }\end{array}$} & \multirow[b]{3}{*}{$\begin{array}{l}\text { Type of } \\
\text { axon }\end{array}$} & \multirow{3}{*}{$\begin{array}{l}\text { Area of } \\
\text { the axo- } \\
\text { plasmic } \\
\text { matrix } \\
\left(\mu \mathrm{m}^{2}\right)\end{array}$} & \multirow{3}{*}{$\begin{array}{l}\text { Density } \\
\text { of } \\
\text { neuro- } \\
\text { fila- } \\
\text { ments } \\
\text { and } \\
\text { microtu- } \\
\text { bules/ } \\
\mu \mathrm{m}^{2}\end{array}$} & \multicolumn{3}{|c|}{$\begin{array}{l}\text { Density of gold } \\
\text { particles } / \mu \mathrm{m}^{2}\end{array}$} \\
\hline & & & & \multicolumn{2}{|c|}{ Glutamate labeling } & \multirow{2}{*}{$\begin{array}{l}\text { Gluta- } \\
\text { mine } \\
\text { label- } \\
\text { ing } \\
\text { Axo- } \\
\text { plas- } \\
\text { mic } \\
\text { matrix }\end{array}$} \\
\hline & & & & $\begin{array}{l}\text { Axo- } \\
\text { plas- } \\
\text { mic } \\
\text { matrix }\end{array}$ & $\begin{array}{l}\text { Axonal } \\
\text { mito- } \\
\text { chondria }\end{array}$ & \\
\hline \multirow[t]{2}{*}{1} & Tonic & 408.5 & 29.5 & 11.4 & $\begin{array}{l}218.3 \pm 29.2 \\
n=9\end{array}$ & 1.5 \\
\hline & Phasic & 486.5 & 40.5 & 6.6 & $\begin{array}{l}75.9 \pm 17.4 \\
n=7\end{array}$ & 1.3 \\
\hline \multirow[t]{2}{*}{2} & Tonic & 472.2 & 26.1 & 13.7 & $\begin{array}{l}270.7 \pm 29.9 \\
n=10\end{array}$ & 2.2 \\
\hline & Phasic & 371.7 & 28.0 & 5.5 & $\begin{array}{l}77.6 \pm 25.2 \\
n=10\end{array}$ & 1.8 \\
\hline \multirow[t]{2}{*}{3} & Tonic & 594.3 & 21.1 & 8.9 & $\begin{array}{l}129.5 \pm 10.2 \\
n=23\end{array}$ & 1.9 \\
\hline & Phasic & 341.7 & 20.5 & 3.7 & $\begin{array}{l}37.4 \pm 16.9 \\
n=21\end{array}$ & 1.6 \\
\hline
\end{tabular}

$n$. Number of mitochondria included in the analysis.

3). To test whether a difference in size could explain the results described above, we turned to the nerve innervating the main extensor muscle of the walking leg (Fig. 5), which contains phasic and tonic excitatory axons of almost the same size. The nerve also contains a smaller inhibitory axon, which was readily identified with GABA immunolabeling (Fig. 5A). Through electron microscopic examination, the phasic and tonic excitatory axons could be readily distinguished; the tonic axon contained larger and more numerous mitochondria than the phasic axon (Fig. $5 B)$.

After immunogold labeling with glutamate antiserum (Fig. $6 A, C$ ) the particle density was again found to be lower in the phasic axon (Fig. 6A) than in the tonic axon (Fig. 6B). Quantitative analysis showed that the levels of glutamate in the phasic axon were at least half of those in the tonic axon, over axoplasmic matrix as well as over mitochondria (Table 2, Fig. 2). Measurement of the cross-sectional area showed that the phasic axon in this nerve was on average slightly smaller than the tonic axon (Table 2), and thus, the difference in glutamate labeling between phasic and tonic axons cannot be attributed to differences in size.

The neurofilaments and microtubules constitute a significant part of the axonal protein content. To examine whether a difference in the density of these elements could be linked to the difference in the concentration of fixed glutamate we performed a quantitative analysis. As shown in Table 2, the density of these structures in the two types of axon was similar, and in some of the nerves it was even lower in the tonic type.

To further examine the basis of the difference in the glutamate labcling, we studicd the distribution of glutamine, which is presumed to be a major glutamate precursor in nerve endings (Fonnum, 1993). Overall, the most intense glutamine labeling occurred in the glial processes surrounding the axons, while the axoplasmic matrix and intraaxonal mitochondria showed relatively weak labeling. As shown in Figure $6, B$ and $D$, the labeling density in axoplasmic matrix was similar between axons of the tonic and phasic type, with only slightly higher levels in the tonic type (Table 2).

\section{Analysis of synaptic regions}

Previous combined electrophysiological and ultrastructural studies have established criteria for morphological identification of terminals of tonic and phasic axons (Atwood, 1967; Atwood and Johnson, 1968; Atwood and Jahromi, 1977; Hill and Govind, 1981; Lnenicka et al., 1986). The terminals of phasic axons are thin and filiform and have comparatively few and small mitochondria, while those of tonic axons are varicose and contain larger and more numerous mitochondria. The synapses in tonic axons generally contain larger clusters of synaptic vesicles at presynaptic active zones. For the leg extensor muscle, the identity of the phasic and tonic terminals has been further confirmed by demonstrating selective uptake of HRP during selective stimulation of the axons (H. L. Atwood and C. K. Govind, unpublished observations).

Tonic and phasic terminals were first identified in serially sectioned areas of the main extensor muscle of the walking leg, using the above criteria. Several terminals which could not be reliably classified were rejected. For each identified terminal a new series of sections was cut and processed with glutamate antiserum. In both types of terminal (Fig. 7), a distinct accumulation of gold particles occurred over the synaptic vesicle clusters, further establishing the transmitter role of glutamate in these terminals. Quantitative analysis showed that the density of gold particles over vesicle clusters was similar in both types of terminal, with an average level of $64.0 \pm 3.7$ and $60.8 \pm 5.6$ in tonic and phasic axons, respectively (mean \pm SEM gold particles $/ \mu \mathrm{m}^{2} ; n=10$ of each type). The level of glutamate labeling over organelle-free axoplasmic matrix and over mitochondria was, however, significantly lower in the phasic (Fig. $7 A C$ ) than in the tonic (Fig. 7A,D-F) type of terminal (Fig. 8). Thus, the difference in glutamate level seen in the main axons is found also in the synaptic terminals of this preparation.

\section{Discussion}

\section{Glutamate levels in tonic and phasic motor axons}

Previous immunocytochemical studies of cell bodies and axons of identified glutamatergic neurons have reported differences in the levels of glutamate immunoreactivity between different classes of neurons (Bramham et al., 1990; Ottersen et al., 1992; Shupliakov et al., 1992; Torp et al., 1992). The physiological

Figure 7. Glutamate immunogold-labeling in morphologically identified phasic and tonic terminals, forming synaptic junctions with the main extensor muscle of the walking leg. $A$, Electron micrograph of an adjacent tonic $(l)$ and phasic (2) axon, including the terminal area of the tonic axon and preterminal area of the phasic axon, respectively. Note the higher number of mitochondrial profiles in the tonic terminal. $B$ and $C$ show examples of phasic synaptic terminals; $D-F$ show tonic terminals. Note that the axoplasmic matrix $(a)$ and mitochondria $(m)$ in the phasic terminals $(A-D)$ exhibit a lower density of gold particles than in the tonic terminals $(C-F)$. Note also the accumulation of glutamate labeling over the synaptic vesicles in both types of terminal. Scale bar, $1 \mu \mathrm{m}$. 

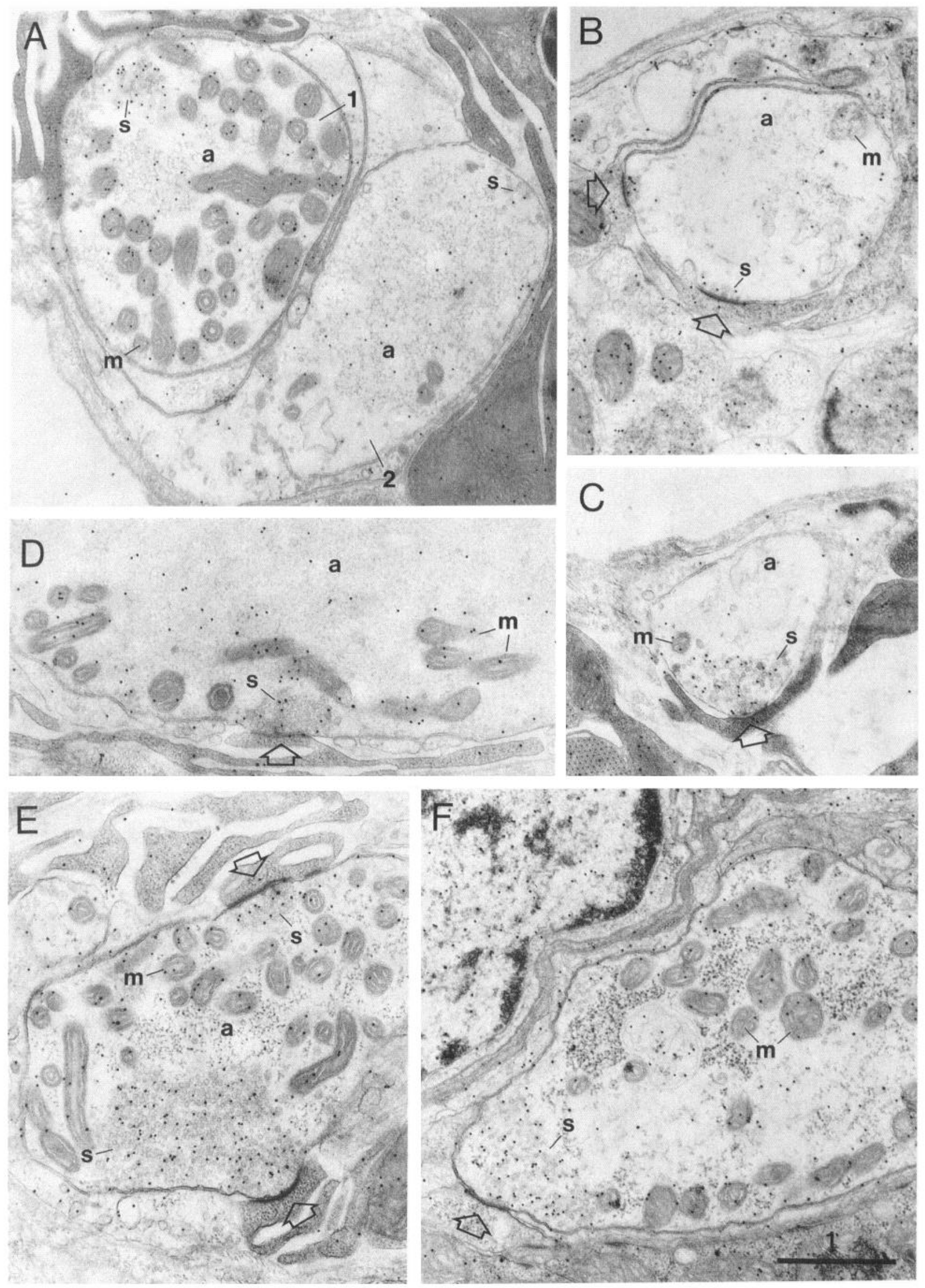

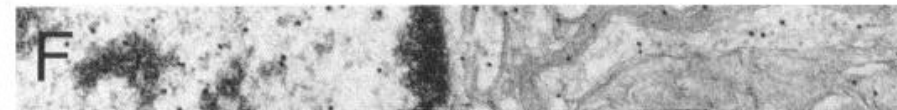

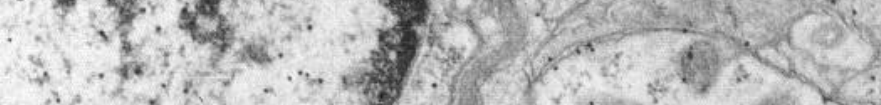

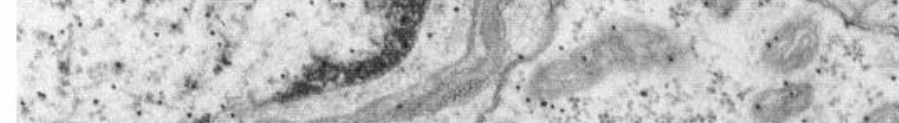

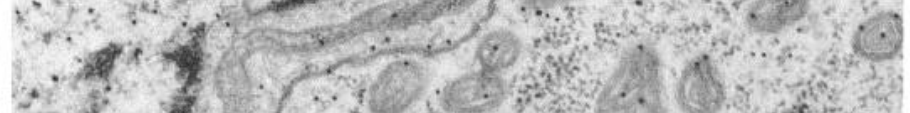

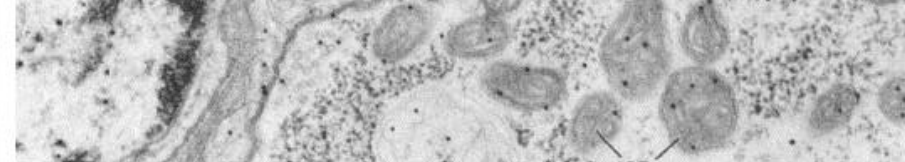

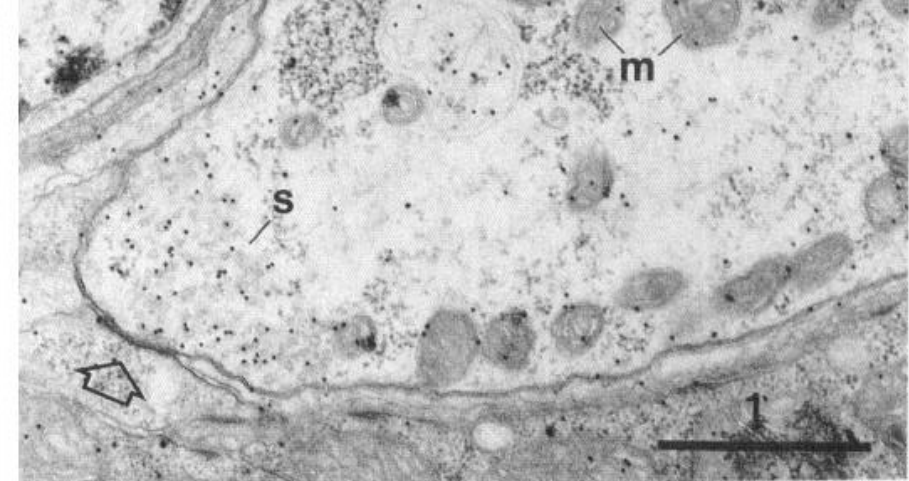




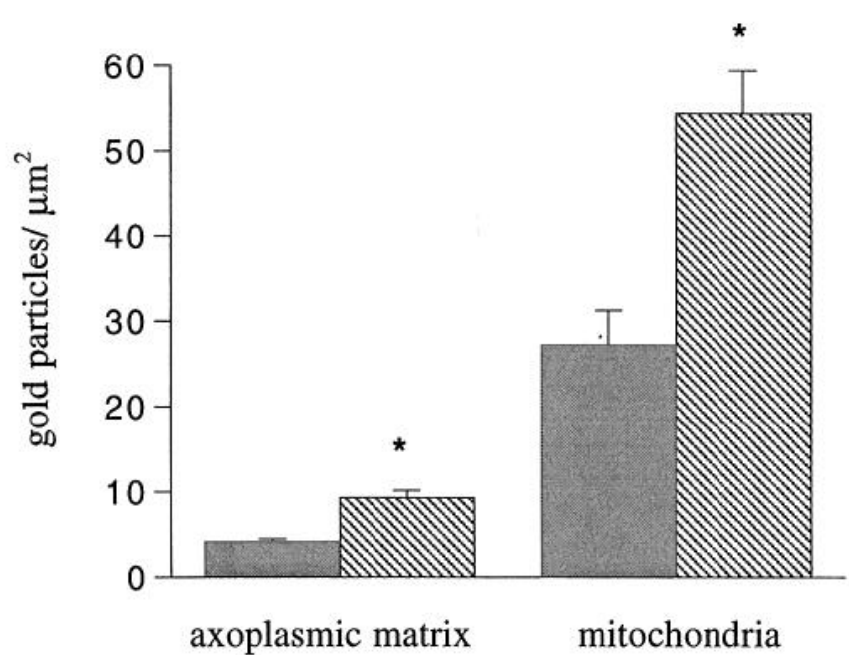

Figure 8. Levels of glutamate-labeling over axoplasmic matrix and mitochondria in terminals of phasic (solid bars) and tonic (hatched bars) axons ( $n=15$ of each type) innervating the main extensor of the walking leg. The mean values were calculated by pooling data from three individual immunocytochemical experiments. Error bars represent SEM. Asterisks indicate statistically significant differences in the levels of glutamate labeling in axoplasmic matrix and mitochondria of tonic axons $(p<0.01$; multiple-range test; Student Newman-Keuls procedure).

significance of these differences has so far been unclear. In the present study, we have sought for a potential link between the axoplasmic glutamate levels and synaptic release properties, using the well-characterized neuromuscular system in crayfish as a model.

In order to judge the significance of the present data, the accuracy of the immunolabeling method, as well as the correspondence between the level of immunolabeling and the free glutamate concentration must first be considered. The antisera employed in this study have all been extensively characterized and shown to be highly selective for fixation complexes of glutamate, with minimal cross-reactivity to other compounds (see Materials and Methods). To ascertain that the specificity was maintained throughout the study, we used test sections (Fig. 1) in all experiments. Moreover, the glutamate antiserum produced a strong labeling of synaptic vesicles in the present study, as in previous studies of glutamatergic synapses (Shupliakov et al., 1992).

The degree of retention of amino acids during fixation is somewhat difficult to determine, as it depends both on the protein content within the studied tissue elements, and on the efficiency of the fixation (Storm-Mathisen and Ottersen, 1990). In the present study, we did not find any evidence to suggest that the difference in the labeling between phasic and tonic axons could be due to differences in protein content. The level of labeling did not correlate with the density of neurofilaments and microtubules. A twofold difference in the axoplasmic level of glutamate labeling was consistently found in different phasic and tonic neurons, irrespective of size and anatomical organization. The mitochondrial labeling also showed a corresponding difference in all specimens studied. Moreover, it seems reasonable to assume that the dissected crayfish axons and terminals, which are directly accessible to fixatives, provide better conditions for an efficient fixation, as compared to most other preparations studied previously, including the mammalian brain. With regard to the analysis of mitochondria and synaptic vesicle clusters it should be noted that the glutamate labeling primarily reflects glutamate present within these organelles, while only a small proportion can be attributed to a tethering of the amino acid to their surface. Thus, the level of labeling over vesicles and mitochondria can vary independently of that over axoplasmic matrix (Castel et al., 1993) and the level of glutamate labeling over synaptic vesicles can be reduced by intense stimulation (Ottersen et al., 1990). A quantitative estimate of the "non-specific" tethering onto vesicles has recently been obtained in large axons in lamprey (Gundersen et al., 1995). The present data thus strongly suggest that tonic axons and terminals contain a higher concentration of free glutamate than phasic axons and terminals. This difference pertains to the axoplasmic matrix and mitochondria, but not to the vesicles, which appear to contain similar levels of glutamate in the two types of axon.

\section{Role of the presynaptic glutamate level in supporting synaptic} vesicle refilling

The results of the quantitative calibration system (Fig. 2) allow the particle density to be used as an index of the concentration of fixed glutamate in the tissue sections (see also Ottersen, 1989). By comparing the particle densities over axoplasmic matrix with those in the quantitative test conjugates (Fig. 2 and experiment 1 , Table 2) the concentration of fixed glutamate in axoplasmic matrix of tonic axons can be estimated to about 4$7 \mathrm{mM}$, while that in phasic axons is half of this or less (cf. Fig. $2 B$ ). Even if a loss of $25-50 \%$ during fixation is assumed (cf. rat brain; Storm-Mathisen and Ottersen, 1990), the free glutamate level will be in the low millimolar range (cf. Shupliakov et al., 1992). The $K_{m}$ value for vesicular glutamate uptake ranges between 0.5 and $2 \mathrm{~mm}$ in different vertebrate species (Tabb and Ueda, 1991). If the transporter in crayfish has similar properties, the axoplasmic concentration of free glutamate should influence the rate at which the synaptic vesicles are filled. The relatively high concentration in tonic axons should thus ensure a rapid refilling of the synaptic vesicles during the release and reformation cycle. The lower concentration of glutamate in phasic axons would produce slower filling of vesicles, compatible with a pattern of intermittent activity and long intervening periods of inactivity. It is not clear at present whether the lower glutamate concentration in phasic neurons would in itself contribute to synaptic depression during sustained activity. Other factors, such as the size of the synaptic vesicle cluster (Pieribone et al., 1995) and/or the rate of reformation/mobilization of vesicles (Brodin et al., 1994; Geppert et al., 1994), could also be important.

The current results strongly suggest that regulation of glutamate accumulation has a different "set point" in phasic and tonic neurons. The mechanisms underlying the supply and regulation of the transmitter pool of glutamate are not yet fully understood. While most available knowledge comes from mammalian systems, at least some of the enzymes implicated in synaptic glutamate metabolism in mammals are known to be similar in crayfish with regard to activity and distribution (Grossfield et al., 1994). Glutamate can be synthesized via several different pathways in neurons (reviewed by Fonnum, 1993). These include synthesis from, for instance, glutamine, glucose, and proline. A direct reuptake may also occur, although it appears to be of limited importance (Gundersen et al., 1995). In the present study, the level of glutamine was found to be similar in tonic and phasic axons. If glutamine is one of the major glutamate precursor in these axons (cf. Grossfield et al., 1994), this would 
suggest that the availability of the precursor is not a limiting factor for the glutamate supply.

A potential regulatory mechanism of the glutamate synthesis in terminal regions of the axon is provided by the stimulation of phosphate-activated glutaminase by $\mathrm{Ca}^{2+}$ and phosphate (Kvamme et al., 1992; Fonnum, 1993). Tonic synaptic activity, which causes frequent rises in presynaptic $\mathrm{Ca}^{2+}$ and presumably a prominent ATP hydrolysis, could thus in itself stimulate the glutamate synthesis. Likewise, if proline is a glutamate precursor in these neurons, stimulation of mitochondrial metabolic activity by increased intracellular $\mathrm{Ca}^{2+}$ (Rizzuto et al., 1994) might influence the synthesis of glutamate by mitochondrial proline oxidase. A test of the general hypothesis that the level of glutamate is directly linked to neuronal aclivity at presynaptic sites would require additional experiments in which the level of activity is controlled and made the same in both neurons well in advance of the glutamate analysis.

With regard to the inhibitory axons in the abdominal nerves the level of glutamate labeling was slightly lower than in the excitatory axons of the same nerve, while those in tonic nerves contained significantly higher levels than those in phasic nerves (O. Shupliakov, L. Brodin, H. L. Atwood, unpublished observation). The pattern of activity and the synaptic properties of these inhibitory axons have not been examined in detail in crayfish, but studies of an analogous system in crab suggest that these parameters resemble those of the excitatory axons (Rathmayer, 1990).

\section{Metabolic differentiation of phasic and tonic terminals}

As a rule the content of mitochondria differs markedly between phasic and tonic terminals in crustaceans; the present results confirmed this observation. Similar observations have been made in vertebrate axons presumed to be divisible into these categories (Shupliakov et al., 1994b). Long-term stimulation of phasic terminals is known to increase their resistance to synaptic depression, and to increase their mitochondrial content (Lnenicka et al., 1986). Conversely, mitochondrial uncouplers have been shown to increase the fatiguability of tonic terminals (Nguyen and Atwood, 1994). Thus, the endurance of synaptic transmitter release is closely linked to functional mitochondria. Scveral processes in the terminal are likely to depend on ATP, including the recycling of synaptic vesicles (Atwood et al., 1972), and the operation of the vesicle fusion machinery (Söllner et al., 1993). However, as some of the potential glutamate-synthesizing enzymes, including phosphate-activated glutaminase and aspartate-amino transferase, appear to be associated with mitochondria (Kvamme et al., 1992; Fonnum, 1993), it is possible that the presynaptic mitochondria content not only reflects the general metabolic competence, but also the capacity for transmitter synthesis in glutamatergic terminals. Brighter rhodamine fluorescence of mitochondria in tonic axons and terminals (Nguyen and Atwood, 1992) suggests that they could be regulated to higher metabolic activity levels than those in phasic axons. Thus, mitochondrial activity is likely to be an important factor in the differentiation and differential physiology of phasic and tonic neurons.

\section{References}

Atwood HL (1967) Variation in physiological properties of crustacean motor synapses. Nature 215:57-58.

Atwood HL (1976) Organization and synaptic physiology of crustacean neuromuscular systems. Prog Neurobiol 7:291-391.
Atwood HL, Jahromi SS (1977) Fast-axon synapses in crab leg muscle. J Neurobiol 9:1-15.

Atwood HL, Johnson HS (1968) Neuromuscular synapses of a crab motor axon. J Exp Zool 167:457-470.

Atwood HL, Wojtowicz JM (1986) Short-term and long-term plasticity and physiological differentiation of crustacean motor synapses. Int Rev Neurobiol 28:275-362.

Atwood HL, Lang F, Morin WA (1972) Synaptic vesicles: selective depletion in crayfish excitatory and inhibitory axons. Science 176: $1353-1355$

Atwood HL, Nguyen PV, Mercier AJ (1991) Activity-dependent adaptation in neuromuscular systems: comparative observations. In: Plasticity of motoneuronal connections (Wernig A, ed), pp 101-114. Amsterdam: Elsevier.

Blackstad TW, Karagülle T, Ottersen OP (1990) MORFOREL a computer program for two-dimensional analysis of micrographs of biological specimens, with emphasis on immunogold preparations. Comput Biol Med 20:15-34.

Bower JM, Haberly LB (1986) Facilitating and nonfacilitating synapses on pyramidal cells: a correlation between physiology and morphology. Proc Natl Acad Sci USA 83:1115-1119.

Bramham CR, Torp R, Zhang N, Storm-Mathisen J, Ottersen OP (1990) Distribution of glutamate-like immunoreactivity in excitatory hippocampal pathways: a semiquantitative electron microscopic study in rats. Neuroscience 39:405-417.

Brodin L, Shupliakov O (1993) Functional diversity of central glutamate synapses-pre- and postsynaptic mechanisms. Acta Physiol Scand 150:1-10.

Brodin L, Shupliakov O, Grillner S (1994) Central glutamatergic transmission: a view from the presynaptic axon. Adv Second Messenger Phosphoprotein Res 29:205-221.

Castel M, Belenky M, Cohen S, Ottersen OP, Storm-Mathisen J (1993) Glutamate-like immunoreactivity in retinal terminals of the mouse suprachiasmatic nucleus. Eur I Neurosci 5:368-381.

Danbolt NC, Storm-Mathisen J, Ottersen OP (1994) Sodium/potassium-coupled glutamate transporters, a "new" family of eukaryotic proteins: do they have "new" physiological roles and could they be new targets for pharmacological intervention? Prog Brain Res 100: $53-60$.

Fonnum F (1993) Regulation of the synthesis of the transmitter glutamate pool. Prog Biophys Mol Biol 60:47-57.

Geppert M, Bolshakov UV, Siegelbaum S, Takei R, De Cannilli P, Hannmer RE, Sudhof TC (1994) The role of rab3a in neurotransmitter release. Nature 369:493-497.

Grossfeld RM, McKinnon E, Hargittai PT, Lieberman EM (1994) Glutamine cycle enzymes in the crayfish medial glant nerve fiber: implications for axon-to-glia signalling. Soc Neurosci Abstr 20:378.1.

Gundersen V, Shupliakov O, Brodin L, Ottersen OP, Storm-Mathisen J (1995) Quantification of excitatory amino acid uptake at intact glutamatergic synapses by immunocytochemistry of exogenous D-aspartate. J Neurosci, in press.

Hill RH, Govind CK (1981) Comparison of fast and slow synaptic terminals in lobster muscle. Cell Tissue Res 221:303-310.

Jahromi SS, Atwood HL (1974) Three-dimensional reconstruction of the crayfish neuromuscular apparatus. J Cell Biol 63:599-613.

Ji Z, Aas JE, Laake JH, Walberg F, Ottersen OP (1991) An electron microscopic, immunogold analysis of glutamate and glutamine in terminals of rat spinocerebellar fibers. J Comp Neurol 307:296-310.

Kanai Y, Smith CP, Hediger MA (1994) A new family of neurotransmitter transporters: the high-affinity glutamate transporters. FASEB J $8: 1450-1459$

Kennedy D, Takeda K (1965a) Reflex control of the abdominal flexor muscles in the crayfish. I. The twitch system. J Exp Biol 43:211227.

Kennedy D, Takeda T (1965b) Reflex control of the abdominal flexor muscles in the crayfish. I. The tonic system. J Exp Biol 43:229-246.

Koerber RH, Mendell LM (1991) Modulation of synaptic transmission at Ia-afferent fiber connections on motoneurons during high-frequency stimulation: role of postsynaptic taget. J Neurophysiol 65:590597.

Kvamme E, Torgner IA, Roberg B (1991) Evidence indicating that pig renal phosphate-activated glutaminase has a functionally predominant localization in the inner mitochondrial membrane. J Biol Chem 266: 13185-13192.

Laake JH, Gundersen V, Nordbø G, Ottersen OP, Storm-Mathisen J 
(1986) An antiserum against glutamine. In: Excitatory amino acids (Roberts PJ, Storm-Mathisen J, Bradford HF, eds), pp 448-450. London: Macmillan.

Lnenicka GA (1991) The role of activity in the development of phasic and tonic synaptic terminals. Ann NY Acad Sci 627:197-211.

Lnenicka GA, Atwood HL, Marin L (1986) Morphological transformation of synaptic terminals of a phasic motoneuron by long-term tonic stimulation. J Neurosci 6:2252-2258.

McNaughton BL (1980) Evidence for two physiologically distinct perforant pathways to the fascia dentata. Brain Res 199:1-19.

Naito S, Ueda T (1985) Characterization of glutamate uptake into syn aptic vesicles. J Neurochem 44:99-109.

Nicholls DG (1993) The glutamatergic nerve terminal. Eur J Biochem 212:502-515.

Nguyen PV, Atwood HL (1992) Electrical stimulation reprograms the metabolic and synaptic phenotypes of crayfish motoneurons. Soc Neurosci Abstr 18:1131.

Nguyen PV, Atwood HL (1994) Altered impulse activity modifies synaptic physiology and mitochondria in crayfish phasic motor neurons. J Neurophysiol 72:2944-2955.

Ottersen OP (1987) Postembedding light- and electron-microscopic immunocytochemistry of amino acids: description of a new model system allowing identical conditions for specificity testing and tissue processing. Exp Brain Res 69:167-174.

Ottersen OP (1989) Postembedding immunogold labeling of fixed glutamate: an electron microscopic analysis of the relationship between gold particle density and antigen concentration. J Chem Ncuroanat 2:57-67.

Ottersen OP, Storm-Mathisen J, Bramham C, Torp R, Laake J, Gundersen V (1990) A quantitative electron microscopic immunocytochemical study of the distribution and synaptic handling of glutamate in rat hippocampus. Prog Brain Res 83:99-114.

Ottersen OP, Zhang N, Walberg F (1992) Metabolic compartmentation of glutamate and glutamine: morphological evidence obtained by quantitative immunocytochemistry in rat cerebellum. Neuroscience 46:519-534.

Parnas I, Atwood HL (1966) Phasic and tonic neuromuscular systems in the abdominal flexor muscles of the crayfish and rock lobster. Comp Biochem Physiol 18:701-723.

Pieribone VA, Shupliakov O, Brodin L, Czernik AJ, Hilfiker-Rotenfluh $S$, Greengard $P$ (1995) Distinct pools of synaptic vesicles in neurotransmitter release. Nature 375:493-496.

Rathmayer W (1990) Inhibition through neurons of the common in hibitory type (CI-neurons) in crab muscles. In: Frontiers in crustacean neurobiology (Wiese K, Krenz W-D, Tautz J, Reichert H, Mulloney B, eds), pp 271-278. Basel: Birkhäuser.

Rizzuto R, Bastianutto C, Brini M, Murgia M, Pozzan T (1994) Mitochondrial $\mathrm{Ca}^{2+}$ homeostasis in intact cells. J Cell Biol 126:11831194.

Shupliakov O, Brodin L, Cullheim S, Ottersen OP, Storm-Mathisen J (1992) Immunogold quantification of glutamate in two types of excitatory synapse with different firing patterns. J Neurosci 12:3789_ 3803.

Shupliakov O, Örnung G, Brodin L, Ulthake B, Ottersen OP, Storm-
Mathisen J, Cullheim S. (1993) Immunocytochemical localization of amino acid neurotransmitter candidates in the ventral horn of the cat spinal cord: a light microscopic study. Exp Brain Res 96:404-418.

Shupliakov O, Atwood H, Mercier AJ, Storm-Mathisen J, Ottersen P, Brodin L (1994a) Levels of presynaptic glutamate immunoreactivity correlate with release properties in tonic and phasic excitatory motor axons. Soc Neurosci Abstr 20:301.9.

Shupliakov O, Gad H, Bakeeva L, Pieribone V, Brodin L (1994b) Organization of mitochondrial pools and synaptic vesicle clusters in glutamatergic axons with different patterns of activity. Eur J Neurosci Suppl 7:117.01.

Söllner T, Whiteheart S, Brunner M, Erdjument-Bromage H, Geromanos S, Tcmpst P, Rothman JE (1993) SNAP receptors implicated in vesicle targeting and fusion. Nature 362:318-323.

Somogyi P, Hodgson AJ (1985) Antiserum to $\gamma$-aminobutyric acid. III. Demonstration of GABA in Golgi-impregnated neurons and in conventional electron microscopic sections of cat striate cortex. J Histochem Cytochem 33:249-257.

Somogyi P, Hodgson AJ, Smith AD, Nunzi AG, Gorio A, Wu Y-J (1984) Different populations of GABAergic neurons in the visual cortex and hippocampus of cat contain somatostatin- or cholecystokinin-immunoreactive material. J Neurosci 4:2590-2603

Storm-Mathisen J, Ottersen OP (1990) Immunocytochemistry of glutamate at the synaptic level. J Histochem Cytochem 38:1733-1743.

Storm-Mathisen J, Leknes AK, Bore AT, Vaaland JL, Edminson P, Haug FM-S, Ottersen OP (1983) First visualization of glutamate and GABA in neurons by immunocytochemistry. Nature 301:517-520.

Tabb JS, Ueda T (1991) Phylogenetic studies on the synaptic vesicle glutamate transport system. J Neurosci 11:1822-1828.

Torp R, Haug FM, Tonder N, Zimmer J, Ottersen OP (1992) Neuroactive amino acids in organotypic slice cultures of the rat hippocampus: an immunocytochemical study of the distribution of GABA, glutamate, glutamine and taurine. Neuroscience 46:807-823.

van Harreveld A (1936) A physiological solution for freshwater crustaceans. Proc Soc Exp Biol Med 34:428-432.

Walberg F, Ottersen OP, Rinvik E (1990) GABA, glycine, aspartate, glutamate and taurine in the vestibular nuclei: an immunocytochemical investigation in the cat. Exp Brain Res 79:547-563.

Wang Y, Floor E (1994) Dynamic storage of glutamate in rat brain synaptic vesicles. Neurosci Lett 180:175-178.

Wiens TJ, Wolf H (1993) The inhibitory motoneurons of crayfish thoracic limbs: identification, structures, and homology with insect common inhibitors. J Comp Neurol 336:261-278.

Wojtowicz JM, Atwood HL (1984) Presynaptic membrane potential and transmitter release at the crayfish neuromuscular junction. $J$ Neurophysiol 52:99-113.

Zhang N, Laake JH, Nagelhus E, Storm-Mathisen J, Ottersen OP (1991) Distribution of glutamine-like immunoreactivity in the cerebellum of rat and baboon (Papio anubis) with reference to the issue of metabolic compartmentation. Anat Embryol 184:213-223.

Zhang N, Storm-Mathisen N, Ottersen OP (1993) A model system for specificity testing and antigen quantitation in single and double labeling postembedding electron microscopic immunocytochemistry. Neurosci Protocols 50:1-20. 